\title{
Aproximación al estudio de la desamortización en Medina Sidonia *
}

\author{
Alberto Ramos Santana
}

Gran parte de las investigaciones sobre el siglo XIX español se centran, en la historiografía más reciente, en el estudio de la poco conocida aún Revolución burguesa española. En palabras de Miguel Izard, "son muchos los especialistas en el siglo XIX español que últimamente coinciden en señalar las características y la cronología de nuestra Revolución burguesa como uno de los puntos clave para una comprensión total de la historia de la pasada centuria... Como han señalado Aracil y García Bonafé, se trata de analizar al grupo beneficiario de las desamortizaciones y construir el modelo específico de la Revolución burguesa española".

(*) Este texto corresponde a la conferencia dada en Medina Sidonia, el día 27 de septiembre de 1989, en la II SEMANA DE MEDINA SIDONIA. Por esta causa se omitieron las citas bibliográficas y documentales en notas a pie de página. Al lector interesado le remitimos, no obstante, la siguientes referencias:

La documentación usada procede del Archivo Histórico Provincial, Sección Desamortización.

Para la Bibliografia consultada remitimos a A. Ramos Santana: La Desamortización civil en Cádiz, en el Bienio Progresista. Cádiz, 1982. A. Muñoz Rodríguez: "La Desamortización de la tierra del siglo XIX en Vejer de la Frontera", en Revista de Estudios Vejeriegos, n 1, 1983. R. Carr: España 1808-1939. Barcelona 1970. V.G. Kiernan: La revolución de 1854 en España. Madrid, 1970, J. Nadal: El fracaso de la Revolución Industrial en España. Barcelona, 1977. B. Clavero: "Política de un problema: La Revolución Burguesa", en: Estudios sobre la R.B. en España. Madrid, 1979. J. Vicens-Vives: $H^{a}$ de España y América, social y económica, vol. V, Barcelona, 1974. M. Ramos Romero: Medina Sidonia. Arte, Historia y Urbanismo. Cádiz, 1981. M. Izard: Manufactureros, industriales y revolucionarios. Barcelona, 1979. 
Para entrar en el tema tendríamos que definir qué entendemos por Revolución Burguesa. Tomamos para ello la definición de uno de los más clarificadores estudiosos de las ideologías de la historiografía reciente: Bartolomé Clavero ha escrito que Revolución Burguesa es: "el establecimiento jurídico del orden preciso (liberación de la propiedad, privatización de la familia, concentración estatal del poder político) para el arraigo, desenvolvimiento y generalizàción... del régimen caracterizado por la prestación del trabajo contra salario, para la determinación sustancialmente mercantil del valor de la capacidad laboral aplicable a medios de producción ajenos al trabajador, valor con ello independiente del efectivamente producido en dicha aplicación; esta revolución jurídica es la Revolución Burguesa".

Centrémonos en una de las primeras ideas aportadas "liberación de la propiedad", de una forma instituida, jurídica, y unamos esta idea a la opinión de Aracil y García Bonafé, por la que estudiar la Revolución Burguesa española "se trata de analizar al grupo beneficiario de las desamortizaciones", y habremos encontrado la justificación de nuestro trabajo. Porque lo que desde ahora debe quedar claro es que la Revolución Burguesa española viene dada desde lo instituido, desde el orden jurídico establecido, donde la propiedad de los medios de producción quedaría instituida y confirmada por las leyes.

Un grupo social, y su evolución en la historia, no puede ser conocido si no estudiamos previamente en qué se apoya su status socio-económico. Es decir, no podemos conocer verdaderamente a un grupo social sin estudiar antes su base económica, o en palabras más conocidas, si no definimos antes su posición respecto a los medios de producción. En el caso de la burguesía española (y de la burguesía en general), ésta va a encontrar uno de sus medios, su justificación e incluso su doctrina en la posesión de los medios de producción, posesión que va a venir favorecida por el apoyo del Estado a esta determinada clase; para que, a su vez, la burguesía sirva de justificación y sustento al Estado en sí.

La Revolución Burguesa española es posible y se justifica desde el momento en que surja una nueva clase de propietarios de los medios de producción que, en defensa de sus intereses de propiedad privada, defienden el establecimiento del Estado burgués. A la vez que éste se justifica por la necesidad de protección al elemento burgués propietario. La propiedad, y su defensa, pues, va a ser a la vez la justificación y principal sustento del Estado burgués. 
La Desamortización va a jugar un papel fundamental en este sentido. Tradicionalmente, la propiedad territorial española llevaba estancada en las manos de un importante, pero reducido, grupo de propietarios desde varios siglos atrás. Se trataba de las propiedades llamadas de manos muertas, amortizadas, donde existía una propiedad jurídica que iba más allá del propietario visible, que se beneficiaba en cada momento de la propiedad pero que en ningún caso podía enajenar. Un ejemplo nos servirá de ilustración. Un monasterio era propietario de una gran finca. La propiedad, era ejercida de forma real por el abad de dicho monasterio, que podía decidir sobre las rentas y beneficios de la propiedad, pero que nunca podía enajenar, transferir, la propiedad, porque no era el propietario jurídico de la finca en cuestión.

Igual sucedía con la propiedad de los ayuntamientos. El cabildo actuaba como propietario real de los bienes municipales, pero nunca podía enajenar la propiedad, que era intransferible y perpetua de los ayuntamientos.

Esto provocó una dejadez de los propietarios jurídicos sobre los bienes que se podían considerar poco rentables, lo que se agravó más en las propiedades municipales, que en gran parte eran desaprovechadas por los municipios, o que, arrendadas desde años atras, proporcionaban unas rentas ínfimas a los ayuntamientos.

Por todo ello, uno de los principales puntos de la Revolución Burguesa va a ser la Desamortización: es decir, la posibilidad de enajenar los bienes amortizados y ser puestos en venta mediante públicas subastas.

Por tanto, como bien ha dicho B. Clavero, el paso primero de la Revolución Burguesa española iba a ser la "liberación de la propiedad," la posibilidad de que dejaran de ser bienes de manos muertas.

La provincia de Cádiz, creemos que puede ser una de las piezas clave para el conocimiento del proceso seguido en esta Revolución Burguesa de la que venimos hablando. Ya los contemporáneos del siglo XIX eran conscientes de la existencia aquí de una incipiente burguesía. M. J. de Larra afirmó que si se quería buscar la denominada clase media mercantil e industrial en España, no se hiciera esto en Madrid, sino en Barcelona y Cádiz, centros productores por excelencia, y primeras próvincias en cuanto a contribución industrial y comercial a lo largo de todo el reinado de Isabel II.

Partiendo de estos presupuestos, un estudio de la desamortización y sus beneficiarios, es decir, los compradores de bienes desamortizados, en Cádiz, nos puede dar fundamento suficiente para intuir una serie de conclusiones respecto a la realidad de la Revolución Burguesa española. 
Si bien es una tarea pendiente e importante el realizar un estudio exhaustivo de la Desamortización en Medina Sidonia y en la provincia en general (trabajo que hace varios años se viene realizando en la Universidad de Sevilla), hay un estudio imprescindible a realizar, que es, como ya hemos dicho, el estudio de los compradores en diferentes términos de nuestra provincia. Para ello puede ser suficiente realizar un muestreo, unas catas en diferentes instantes de los procesos desamortizadores dados en el reinado de Isabel II, fijándonos, no sólo en detalles específicos de las subastas, sino en sus consecuencias.

Para el caso que nos ocupa hemos analizado dos grupos de subastas y posteriores ventas en los períodos esenciales de la Desamortización: la de Mendizábal y la de Madoz, estudiando unos cuarenta casos de 1837 y 1861 , fundamentalmente.

Para adentrarnos en el tema que proponemos, esto es, conocer las consecuencias sociales y beneficiarios de la Desamortización en Medina Sidonia, dentro del contexto general de la Revolución Burguesa española, tenemos, necesariamente, que recordar brevemente los motivos reales por los que se inició el proceso desamortizador, puesto que, sin dudarlo, ya de la normativa desamortizadora y de las razones que la justificaban se pueden deducir unas primeras hipótesis de trabajo e intuir el resultado lógico del proceso.

Efectivamente, las raíces de la Desamortización se localizan en la política ilustrada del Siglo XVIII. Amortizaciones, vinculaciones y mayorazgos, provocaron una disminución de los rendimientos de las tierras, la despoblación y la reducción de ingresos fiscales, siendo todo ello un factor decisivo de la decadencia española, tal y como denunciaran Jovellanos, Campomanes u Olavide, entre otros muchos.

Como es conocido, la necesidad de buscar soluciones a este problema condujo a los procesos desamortizadores, en cuatro períodos principales:

1) Reinado de Carlos IV y medidas de José I.

2) Trienio Constitucional.

3) Desamortización de Mendizábal.

4) Ley Madoz de 1855, aunque su desarrollo principal se diera a partir de 1860.

Centrándonos en estos dos últimos períodos, para comprender la política desamortizadora de los liberales iniciada por Mendizábal, tenemos que fijarnos en los problemas hacendísticos y en los aspectos políticos de su desarrollo legislativo, y concluir que los motivos principales que condujeron a la Desamortización fueron: 
a) En el aspecto social, el deseo de reforma de la propiedad agraria, para beneficiar a los campesinos, a la producción y al Estado.

b) En el aspecto económico-financiero se pretendía obtener mayores ingresos fiscales, puesto que la venta de los bienes eclesiásticos acabaría con las situaciones de privilegio de dichos bienes, que no pagaban tributos. Al mismo tiempo el producto de la venta permitiría amortizar la Deuda Pública.

c) Aspecto político: sufragar, en primera instancia, los gastos de las guerras Carlistas y atraer a la postre a muchos españoles hacia el liberalismo, si no por convicción ideológica, al menos por egoísmo.

Sobre estas razones volveremos al analizar la legislación Madoz. En marzo de 1836 se conoció el Real Decreto por el que se declaraban extinguidos - con algunas excepciones - los monasterios, conventos, colegios, congregaciones y demás casas de religiosos, adjudicándose al Estado sus bienes y ordenando su venta.

A esta normativa, iniciadora de la Desamortización más famosa y más atacada, se unió la ley de julio de 1837 , por la que las propiedades del clero secular pasaban a ser bienes nacionales. (Aunque esta segunda oleada desamortizadora no entró en vigor hasta diciembre de 1841).

Como es conocido, la normativa de 1836 daba grandes facilidades a los compradores, que al hacer la escritura de transmisión de dominio sólo estaban obligados a satisfacer la quinta parte del precio, concediéndoseles un plazo entre 9 y 16 años, según fuese la moneda a emplear, ya que se admitían los títulos de todas las deudas reconocidas por el Estado y por su valor nominal, a pesar de su reconocida devaluación.

Más significativa y clarificadora se nos antoja la normativa emanada de Pascual Madoz, puesto que no hay que echar en olvido que el movimiento progresista de 1854 , estudiado por Kiernan, se ha considerado como un movimiento revolucionario genuinamente burgués-liberal, predecesor de 1868, y, para el ya nombrado Kiernan, con posibles relaciones con el movimiento europeo de 1848 .

En 1854 se intentó una revolución perdurable y regeneradora. Pero el movimiento fue un fracaso evidente en un par de años. Sin embargo, R. Carr ha dicho que pensar solamente en el fracaso político es malinterpretar el significado del bienio: "El llamamiento a los intereses materiales... se convirtió en el credo regenerador... El acto de fe simbólico en los beneficios de la expansión y la expresión característica del brote de confianza económica que acompañaron a la revolución, fue la codificación y ampliación por Madoz de las lejes desamontizadonas". 
No obstante, no hay que caer en el error de considerar a la Desamortización como una consecuencia directa de la Vicalvarada. Había, como hemos dicho, un origen mucho más profundo, que podemos dividir, como en el proceso de Mendizabal, en dos causas generales: económicas y políticas.

Los largos e inacabados problemas de la Hacienda española fueron la motivación principal a la que se hizo alusión para iniciar el proceso desamortizador; veámoslo brevemente. En el paso del siglo XVII al XIX, el régimen económico no había cambiado. En 150 años la economía española no había sufrido transformaciones importantes. Sin embargo, la población ha aumentado. La desproporción que se va creando, entre los mayores gastos y unos ingresos que no aumentan prácticamente nada, llevaron a la hacienda española al déficit constante. El recurso de los préstamos a interés, vigentes en la economía española desde el siglo XVI, ya no eran una solución válida.

La deuda del Estado es descrita por Nadal como una inmensa bola de nieve, que aumenta a cada vuelta, y cada parche iba engordando de tal modo, que los recursos tradicionales, estancados en sus límites, se convirtieron en inoperantes para frenar la gigantesca bola. Había que frenarla con un obstáculo nuevo. Había que crear unas fuentes de ingresos nuevas.

La relación directa de la Desamortización con la deuda pública, la expuso el propio Pascual Madoz, al declarar una deuda en 1855 que superaba los $820.000 .000 \mathrm{r}$., justificando así la necesidad de re-instaurar las medidas de Mendizábal.

Intimamente ligadas a las causas económicas, las políticas. El enfrentamiento partidista, que se dio en casi todos los asuntos públicos en el segundo tercio del siglo XIX, llevaba a disputas, a veces puramente bizantinas. Bastaba que un partido apoyara una idea para que el otro se proclamara en contra de la misma.

La Desamortización se convirtió en una bandera de combate ideológico, levantada por el grupo progresista, que se consideraba a sí mismo como integrado por una burguesía revolucionaria. Los progresistas buscaban, en efecto, el apoyo de la burguesía mercantil, ávida de poder económico y político, que será la propulsora y beneficiaria de la Desamortización. La Desamortización significaba según esto un paso más de la revolución liberal burguesa, iniciada desde las Cortes de Cádiz. Finalidad revolucionaria que no ocultaba la Comisión de Desamortización, cuando enfáticamente anunciaba "...el golpe mortal contra el abominable viejo régimen". 
La búsqueda de este apoyo, del apoyo de un determinado grupò social, es algo indudable, ya desde la misma normativa desamortizadora. Pese a las bellas palabras de que se deseaba formar una clase de pequeños propietarios y productores directos de sus propios bienes, la realidad legislada contradecía las palabras de la Comisión de Desamortización. Las leyes de 1 de mayo de 1855 y 31 de mayo de 1855 determinaban claramente quiénes se podían beneficiar de la desamortización. La primera, diferenciaba entre fincas de mayor cuantía o menor cuantía. Las de mayor cuantía eran las que se tasaban en más de 10.000 rs. Las de menor cuantía eran las que no alcanzaban tal cantidad en su tasación.

A las primeras, las de mayor cuantía, solo podían aspirar, según la ley de 31 de mayo de 1855, aquellos españolitos que pagaran 500 ó más rs. de contribución. Es decir, que se limitaba el número de posibles compradores a aquellos que tuvieran una propiedad que sirviera de garantía a la venta a plazos de los bienes adjudicados. (En el caso de no contribuir con los 500 rs. se podía participar en la subasta con un fiador conocido que pagara esos 500 rs. de contribución directa anual).

Si recordamos que la legislación censitaria del reinado de Isabel II sólo permitía votar desde 1845 a los que pagaran más de 400 rs. de contribución estatal, y esto limitaba el sufragio a poco más del $2 \%$ de los españoles, se deduce fácilmente que los posibles compradores de bienes desamortizados debían pertenecer a un grupo social minoritario y privilegiado, e inferior a ese $2 \%$ de posibles votantes.

Como vemos, ya la misma legislación de P. Madoz, al que Vicens ha calificado como el más genuino representante de la burguesía financiera catalana, limitaba el número de posibles compradores a un grupo social muy señalado. Las fincas cuya tasación era menor de 10.000 rs. eran naturalmente las que menos beneficios podian aportar, y hay que señalar que, en Cádiz, pocas fincas fueron consideradas de menor cuantía.

Centrándonos, ahora, en el proceso concreto que nos ocupa, hay que decir que, tanto en la desamortización de Mendizábal como en la de Madoz, se pusieron en venta un notable número de hectáreas de tierras de Medina. Nosotros hemos realizado una muestra que consideramos muy aceptable en 1837 y 1861.

Concretamente en el período comprendido entre 1836-39, período álgido de la Desamortización Mendizábal, Marcos Romero señala que se desamortizaron en Medina Sidonia, 1.405 Ha. procedentes de bienes de conventos. En nuestra muestra analizaremos $872 \mathrm{Ha}$, es decir, el $62 \%$ de las tierras conventuales puestas en venta.

Para el periodo 1861-1879, el mismo autor señala que se subastaron $960 \mathrm{Ha}$. procedentes de propios. En nuestra muestra analizaremos $675 \mathrm{Ha}$, es decir, el $70 \%$ de las tierras puestas en venta.

Las fincas puestas en subasta en 1837 que nosotros hemos estudiado son: 


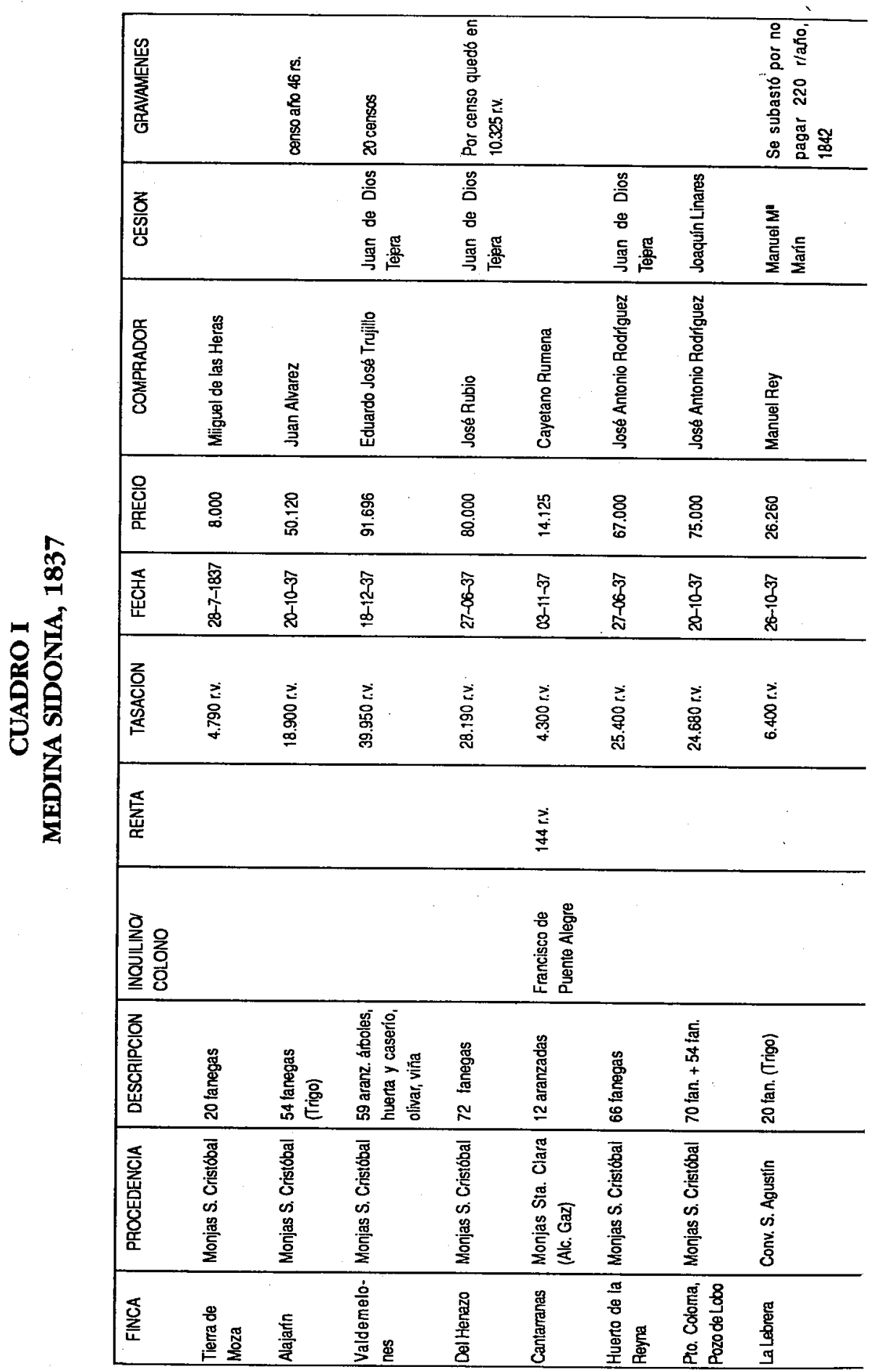




$$
\stackrel{\geq}{ \pm}
$$

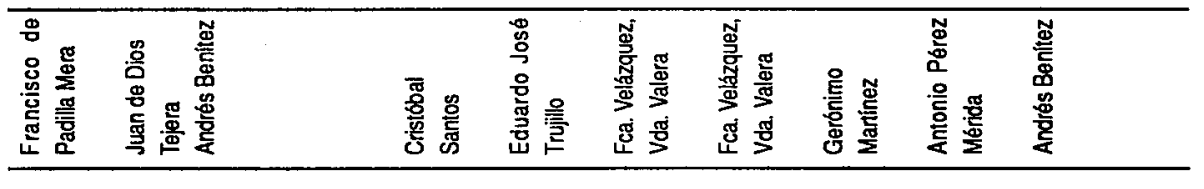

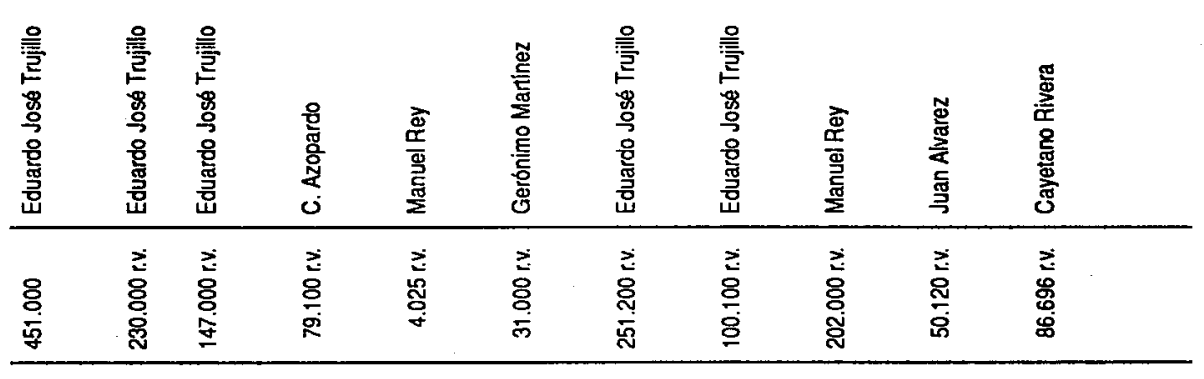

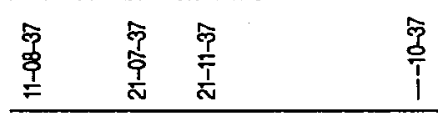

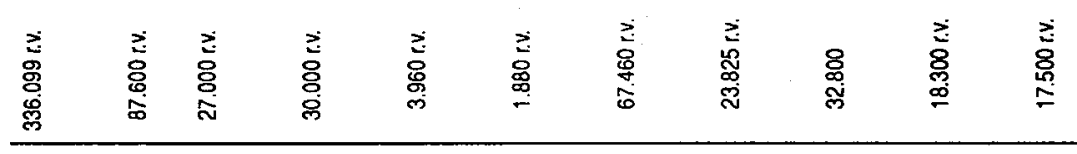

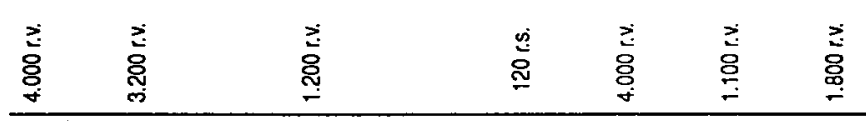

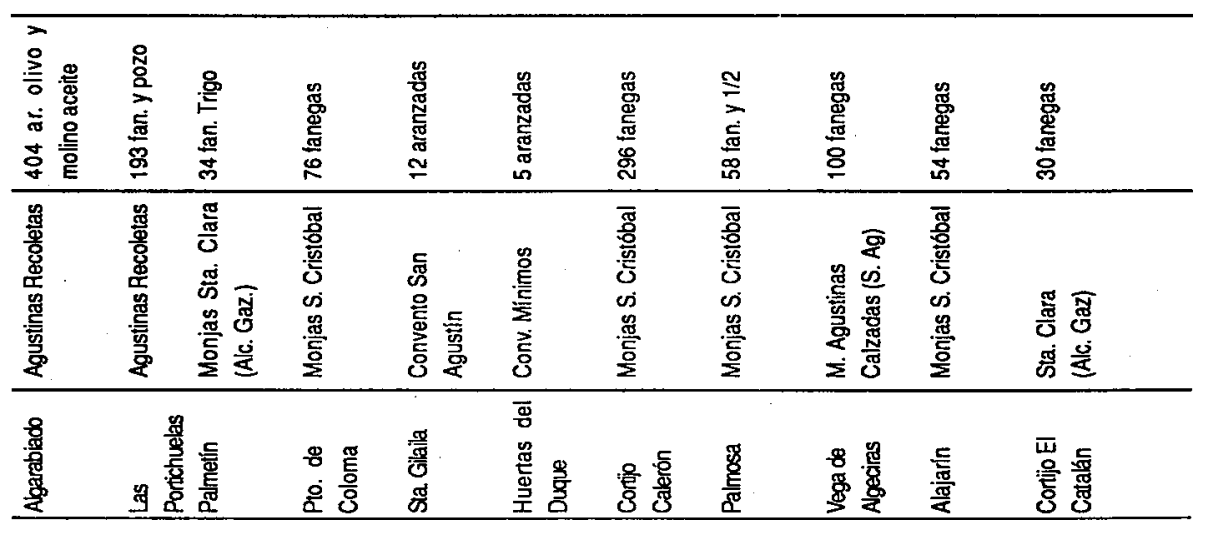



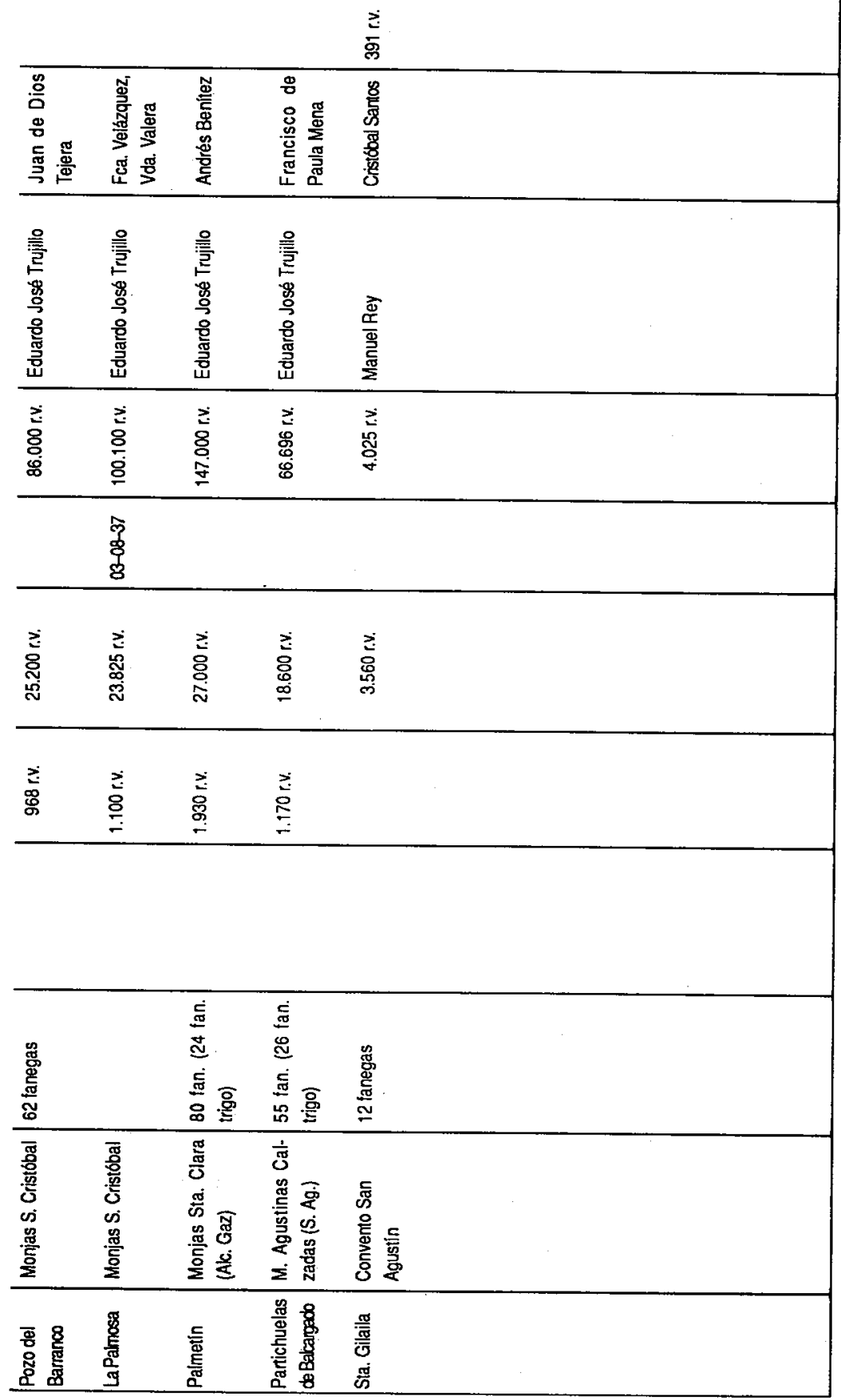

106 
Procedente, por tanto, de:

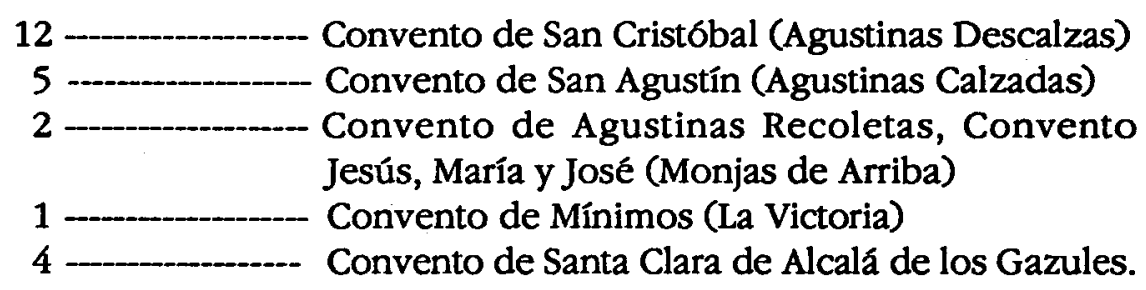

En total suman las $872 \mathrm{Ha}$. señaladas anteriormente.

Todas estas fincas estaban arrendadas, aunque sólo conocemos el nombre de un arrendatario, el de Francisco de Puente Alegre, que era colono de la finca de Cantarranas, de las monjas de Santa Clara de Alcalá de los Gazules, de 12 aranzadas $(4,5 \mathrm{Ha})$, por la que pagaba 144 r.v. anuales.

Aunque la cantidad del arrendamiento no es - con la documentación al uso- totalmente significativa. Por ejemplo, el convento de Mínimos percibía por 5 aranzadas $(1,8 \mathrm{Ha})$ de la Huerta del Duque 120 rs. Compárese con el caso anterior. Por eso, mientras no sepamos exactamente los cultivos (y producción) a los que se destinaban, en la fecha del arrendamiento, no podremos saber la razón de la diferencia de rentas.

Sí tiene mayor interés la tasación fijada por los expertos, que se hacía, no sólo en relación a lo que las fincas producían anualmente, sino a lo que los mismos consideraban que se podía llegar. Siguiendo con el ejemplo antes puesto, la finca de Cantarranas (4,5 $\mathrm{Ha}$, renta de 144 r.v./año) se tasó en 4.300 r.v. para la subasta. La Huerta del Duque $(1,8 \mathrm{Ha}, 120$ r.v./año) se sacó a bubasta en 1.880 r.v. Observamos así una relación proporcional entre la extensión y la tasación.

Pero tampoco esto puede establecerse - lógicamente- como norma fija. Conocer la dedicación y producción de la tierra puesta en venta parece fundamental. Otro ejemplo puede aclarar lo que decimos. El Cortijo Calerón (monjas de San Cristóbal) de 139 Ha. - del que no sabemos su dedicación exacta- se tasó en 67.460 r.v.; mientras que las Portichuelas (Agustinas Recoletas), de $90 \mathrm{Ha}$. y un pozo, se tasó en 87.600 r.v.; o la finca El Algarabiado (de la misma institución) de la que se indica tiene olivos y molinos aceiteros, con $151 \mathrm{Ha}$, se tasó en 336.099 r.v. Tanto la finca El Algarabiado como el Cortijo Calerón proporcionaban 4.000 r.v./año. 
Lo que tiene mayor interés es las cantidades que se alcanzaron en los remates. El conjunto de las fincas que hemos estudiado, vendidas en 1837, se tasaron por los peritos en 897.219 r.v.; sin embargo, en los remates de las subastas su precio alcanzó los 2.448 .263 r.v., es decir, casi tres veces más de lo establecido por la comisión de peritos. Exactamente el $272 \%$ más caro de lo tasado.

Con motivo la de llamada desamortización Madoz —aunque sus efectos en Medina Sidonia sean posteriores a la renovación del proceso obra de O'Donnell-, se pusieron en venta, bienes de propios, entre 1861 y 1879 (como antes indicamos) $960 \mathrm{Ha}$. Las fincas de las que hemos analizado el expediente suman $675 \mathrm{Ha}$ (el 70\%), y son: (véase Cuadro 2).

En total once fincas, de las que conocemos el nombre de su colono en nueve casos. Destacan las suertes números 1,4 y 5 de la Cañada del Valle, arrendadas a Francisco Pérez Noriega y los números 3 y 5 de la Dehesa del Torero arrendadas a la familia de Miguel Díaz Camacho.

Aunque en las cantidades a pagar por los arrendamientos hay una mayor proporcionalidad en la relación extensión/precio en las tierras de propios, también vemos casos de desproporciones inexplicables para nosotros en este momento. Por ejemplo, las 190 fanegas de acebuches y alcornoques arrendadas por José $\mathrm{M}^{2}$ Navarro en la Dehesa del Picazo, proporcionaban a los propios 190 r.v./año. Sin embargo, las 100 fanegas, también de acebuches y alcornoques, que los Díaz Camacho cuidaban en la suerte tercera de la Dehesa del Torero, proporcionaban 600 r.v./año.

El conjunto de las fincas de propios que hemos estudiado se tasó para su puesta en venta en 395.813 r.v., alcanzando en los remates un precio de 446.450 r.v. por el total subastado, lo que supone un aumento del $117 \%$ de lo tasado, proporción corta comparada con el aumento de 1837, pero que se puede explicar por la situación de cierta desconfianza general en la economía española vigente en la década de los sesenta del pasado siglo.

Una vez que hemos repasado rápidamente los resultados de las ventas, tenemos que volver al aspecto que los expertos consideran de mayor interés: los compradores de las tierras y las consecuencias de las compras. Para ello debemos enlazar con las consideraciones que hacíamos al iniciar esta charla: ¿A qué sector social pertenecen los compradores de las fincas desamortizadas? 


\begin{tabular}{|c|c|c|c|c|c|c|c|}
\hline 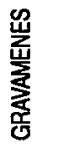 & & & & & & & \\
\hline 䓛 & 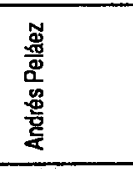 & 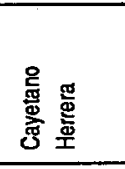 & 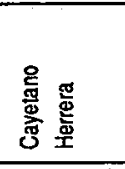 & 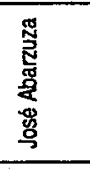 & 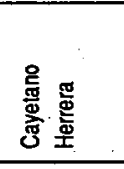 & 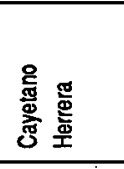 & 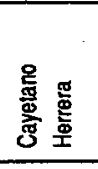 \\
\hline 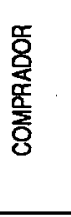 & 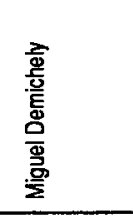 & 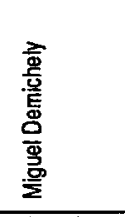 & 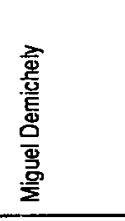 & 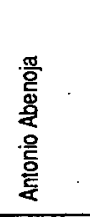 & 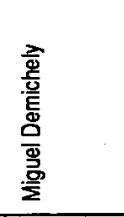 & 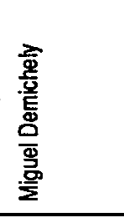 & 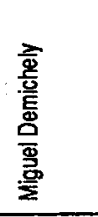 \\
\hline 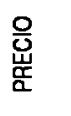 & 迆 & 京 & 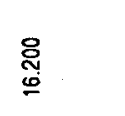 & $\begin{array}{l}\text { : } \\
\text { : }\end{array}$ & 옹 & 怘 & 욿 \\
\hline $\begin{array}{l}\text { 졿 } \\
\text { 世 } \\
\end{array}$ & $\frac{\bar{\varphi}}{\overline{\bar{g}}}$ & $\begin{array}{l}\bar{\Phi} \\
\underline{\underline{\underline{\phi}}}\end{array}$ & $\begin{array}{l}\bar{\phi} \\
\overline{\underline{\phi}} \\
\end{array}$ & $\begin{array}{l}\bar{\Phi} \\
\overline{\bar{g}} \\
\end{array}$ & $\begin{array}{l}\bar{\phi} \\
\overline{\bar{g}}\end{array}$ & $\frac{\bar{\varphi}}{\bar{g}}$ & $\begin{array}{l}\bar{\Phi} \\
\overline{\bar{\phi}} \\
\end{array}$ \\
\hline 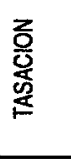 & 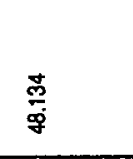 & $\begin{array}{l}\stackrel{8}{0} \\
\stackrel{0}{0}\end{array}$ & $\stackrel{\circ}{\stackrel{0}{+}}$ & 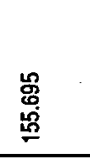 & 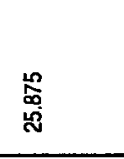 & 总 & 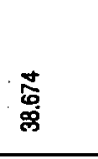 \\
\hline 芘 & : & 总 & 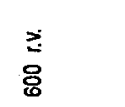 & 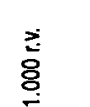 & 总 & 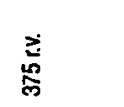 & 音 \\
\hline 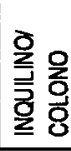 & 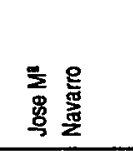 & 总蒙 & 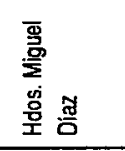 & 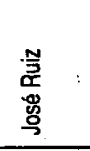 & 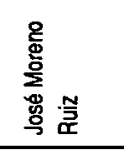 & 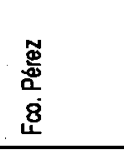 & \\
\hline 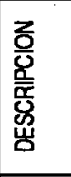 & 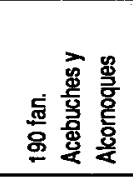 & 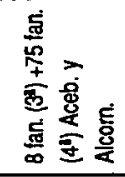 & 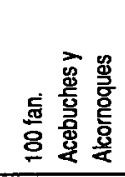 & 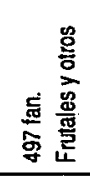 & 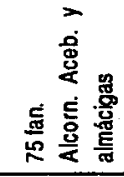 & 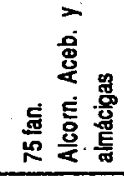 & 曋 \\
\hline 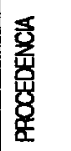 & $\frac{\alpha}{2}$ & $=$ & $=$ & $=$ & . & $=$ & $=$ \\
\hline $\begin{array}{l}\frac{\Phi}{4} \\
\frac{\underline{2}}{4} \\
\end{array}$ & 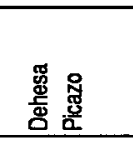 & 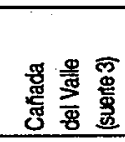 & 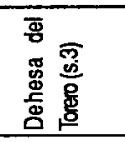 & 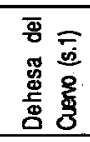 & 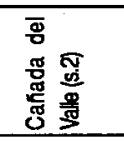 & 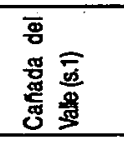 & 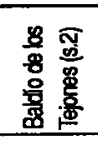 \\
\hline
\end{tabular}




\begin{tabular}{|c|c|c|c|}
\hline 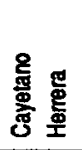 & 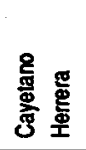 & 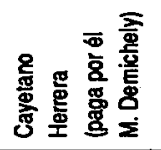 & 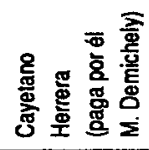 \\
\hline 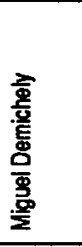 & 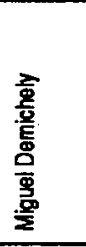 & 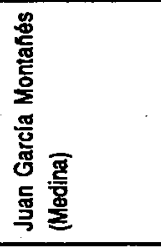 & 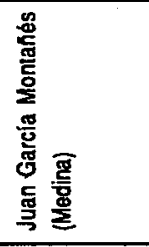 \\
\hline$\frac{\stackrel{2}{0}}{8}$ & $\frac{8}{=}$ & 8 & 8 \\
\hline$\frac{\bar{\Phi}}{\bar{\phi}}$ & $\frac{\bar{\Phi}}{\bar{s}}$ & $\frac{\Phi}{\Phi}$ & $\frac{\bar{\phi}}{\bar{\Phi}}$ \\
\hline $\begin{array}{l}\overline{8} \\
\overline{8}\end{array}$ & 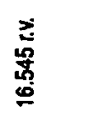 & 胥 & 莫 \\
\hline 항 & : & 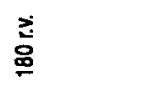 & 每 \\
\hline
\end{tabular}

\begin{tabular}{|c|c|c|c|}
\hline & 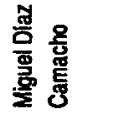 & 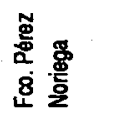 & 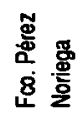 \\
\hline 동 & 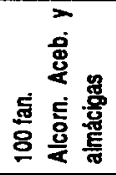 & 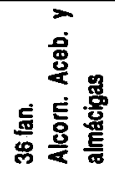 & $\frac{\text { 鬲 }}{\mathbb{8}}$ \\
\hline
\end{tabular}

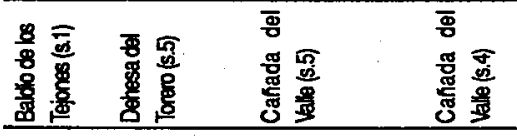


Pero, antes de introducirnos en el estudio de los compradores, van a permitir que haga un par de acotaciones. En los procesos de Desamortización intervienen, no solamente los que se van a convertir en nuevos propietarios, sino que hay que contar con un elevado número de licitadores, corredores... agiotistas, en suma, que iban a encarecer el producto. En muchos casos, llegarían a efectuar el remate de la subasta, es decir, a comprar la finca puesta en licitación, para cederla inmediatamente a otro personaje. Este mecanismo de las cesiones es uno de los fenómenos que más interés despiertan en la investigación sobre Desamortización. Hay dos posibilidades: que el rematante sea un testaferro del que va a ser auténtico comprador.

$O$, sencillamente, que se efectúe una reventa sobre la finca subastada. Esto podía ser un gran negocio. Como saben, se podía comprar con títulos de la deuda pública, que por entonces estaban muy devaluados. Es decir, comprar con papel del Estado, que se consideraba prácticamente imposible de colocar, y vender luego en metálico, podía convertirse en un magnífico negocio. Por otra parte, el Estado recuperaba títulos de la Deuda Pública, lo que también le interesaba.

Aunque el pago con títulos de la Deuda Pública se dio con cierta frecuencia, en Medina Sidonia sólo hemos localizado un caso en el que se señala explícitamente, lo que no es común. En 1837 se pagó así la finca del Henazo, rematada en 80.000 r.v. y que pagó Juan de Dios Tejera, comprador de otros lotes en los que no se señala la forma de pago.

Lo que fue realmente llamativo en Medina Sidonia fue la labor de los intermediarios, es decir, de aquellos que -como hemos señalado- eran simples testaferros o compraban para negociar. Hay algunos datos que nos permiten intuir la diferencia entre unos y otros, pues los primeros -de los que más adelante pondremos algunos ejemplos- eran auténticos profesionales intermediarios.

Del total de casos estudiados, sólo en cuatro observamos que el rematante de las subastas se adjudica la propiedad definitivamente. Supone el $11 \%$. En el $89 \%$ restante se compra para ceder a un nuevo propietario.

Los cuatro casos citados se dan en 1837, siendo los rematantes Miguel de las Heras (Tierra de Mora, 8.000 r.v.); Juan Alvarez (Alajarín, 50.120 r.v.); Cayetano Rumena (Cantarranas, 14.125 r.v.) y Carlos Azopardo (Pto. de Coloma, 79.100 r.v.). 
La labor del intermediario, del que compraba para ceder, èa de profesional.

En Medina Sidonia encontramos dos casos concretos -entre otros varios- absolutamente ejemplares. Son los casos de Eduardo José Trujillo, en 1837, y Miguel Demichely, en 1861. El primero consiguió 10 remates (más una cesión) que cedió inmediatamente a diferentes personas, aunque en tres ocasiones fue a Juan de Dios Tejera.

El caso de 1861 es aún más llamativo. De once subastas, Miguel Demichely remató personalmente 8 , y en dos más usó un socio de Medina Sidonia, Juan García Montañés, que cedió, siguiendo las instrucciones de Demichely. Y de las diez propiedades en cuya compra participó Demichely, 9 terminaron en las mismas manos: Cayetano Herrera.

Es hora, pues, que nos fijemos en algunos aspectos concretos biográficos de los participantes en la desamortización en Medina.

Hemos seleccionado y averiguado información sobre algunos de los rematantes y propietarios definitivos.

Los casos de Eduardo José Trujillo y Miguel Demichely parecen claros: eran dos gaditanos, corredores de fincas, que trataron y lograron hacer de su labor un importante y productivo negocio, logrando sustanciosos beneficios. Ambos participaron en otros puntos de la provincia, dejando, en el caso de Trujillo, importante herencia a su familia, según se desprende del trabajo de Antonio Muñoz sobre la desamortización de Vejer.

Otros casos son los de:

Juan Alvarez, rematante en dos ocasiones, aunque una de las fincas la cedió a Antonio Pérez Mérida. Era natural de Morón, aunque vecino de Cádiz, donde vivía (hacia 1865) en la calle Cardoso $\mathrm{n}^{\circ} 1$. Soltero, con él residían el dependiente de la farmacia de su propiedad y un estudiante, además de un sirviente.

Como queda dicho, Juan Alvarez era farmacéutico, aunque también está censado como propietario. Tenía a su cargo la farmacia oficial —además de una privada - del Hospital de Mujeres de Cádiz. Era uno de los 32 propietarios más ricos de Cádiz. Participó de forma intensa en la Desamortización en varios puntos de la provincia de Cádiz: Espera, Grazalema, Cádiz, Sanlúcar, Arcos, además de Medina.

El caso de Carlos Azopardo es uno de los más llamativos que se pueden localizar. Azopardo era miembro de una conocida familia gaditana, vivía (hacia 1856) en la Plaza de Mina 14, de Cádiz, con varios hijos y cinco criados. 
Aparece ya en la relación de gremios de 1821 como mercader è telas con tienda de tercera clase. Sin embargo, su especialización en tejidos le hizo progresar rápidamente, convirtiéndolo en uno de los propietarios y. comerciantes de tejidos más considerados en la provincia, hasta el extremo de conseguir encargos como el de 960 uniformes para la Milicia Nacional en agosto de 1855 , mediante subasta, que entregó al mes siguiente. Fue también accionista del ferrocarril gaditano, según señala El Comercio de 10 de junio de 1855.

Políticamente fue un convencido liberal, con tintes revolucionarios: participó en el movimiento de 1820 con Riego y Quiroga, e incluso después del triunfo liberal de 1836 , su radicalización le llevó a ser condenado al destierro en Mallorca en 1838. Su buena bolsa le sirvió para suavizar la condena. Su defensa de la causa liberal le llevó a ser elegido comandante del Tercer Regimiento de la Milicia Nacional en 1840.

Su participación en la Desamortización fue muy importante en Cádiz, Espera, Grazalema, El Puerto de Santa María, Vejer, Sanlúcar, Medina, etc. Aunque su interés era generalmente especulativo, en el caso de Medina parece se quedó con la suerte Puerto de Coloma que compró por 79.100 r.v.

Manuel Rey Trujillo era un caso típico de comerciante: remataba fincas, en principio para él, pero si el beneficio que podía obtener por un traspaso merecía la pena, no lo dudada. Fue lo que hizo en Medina, que cedió las cuatro fincas subastadas a Manuel Mª Marín, Gerónimo Martínez y Cristóbal Santos (2 fincas).

Manuel Rey Trujillo había nacido en Jerez, aunque residía en Cádiz. Hacia 1853 vivía en la calle Mateo de Alba con su mujer, cuatro hijos, la suegra y un criado.

En el casillero profesión se sitúa siempre la palabra Propietario, aunque tuvo una participación muy activa en la vida gaditana. Fue Regidor del Ayuntamiento gaditano, Caballero Comendador de la R. O. de Carlos III (concedido por su labor durante la epidemia de cólera de 1854), miembro de la Milicia Nacional, de la Junta Filantrópica de la Cárcel y de la del Ferrocarril.

Su actividad en la Desamortización, además de Medina se extendió por Cádiz, Espera, El Puerto de Santa María, Sanlúcar, Rota, Vejer, etc.

Sin que tengamos información de si participó en las subastas, el propietario de Medina Cristóbal Santos recibió la "cesión" de dos propiedades por Manuel Rey Trujillo. Como es sabido, Cristóbal Santos, aparte de agricultor y propietario, fue alcalde de Medina Sidonia. 
Un caso importante es el de Cayetano Herrera. Como hèmos señalado, a través de Miguel Demichely, Herrera adquirió 9 fincas en 1861 , con un total de 752 fanegas, es decir, $353 \mathrm{Ha}$, algo más del 50\% de lo vendido.

De Cayetano Herrera sabemos que vivía en Sevilla, siendo Magistrado de la Audiencia Territorial, y estando representado en Cádiz por Francisco Bastarreche.

La única finca que Demichely no cedió a Herrera, la adquirió el propietario de Moguer Andrés Peláez.

Aunque sólo adquiriera una finca, es importante el caso de José Abarzuza, quien a través del intermediario gaditano Antonio Abenoja compró la suerte número 1 de la Dehesa del Cuervo, de $233 \mathrm{Ha}$, por 200.000 r.v.

José Abarzuza era un comerciante nacido en Cádiz, de unos 496 50 años. En 1865 aparece como uno de los 30 más ricos contribuyentes de Cádiz capital. Estaba casado con Teresa Ferrer, nacida en Cuba, con la que vivía en una buena casa de la calle Murguía 53, en uno de los barrios más ricos de Cádiz, el de las Cortes. Tenía 3 hijos, dos de ellos nacidos durante su estancia de negocios en Cuba.

Tan sólo por sus apellidos, Abarzuza e Imbrech, sabemos que era de rancia estirpe adinerada de la provincia. Su nivel económico era alto, como se deduce anecdóticamente de los cuatro sirvientes que atendían a la familia; más rigurosa, sin embargo, es la relación de sus propiedades y ocupaciones.

Abarzuza se definía a sí mismo como Propietario y Comerciante. Fue accionista del "Banco de Cádiz", de la "Compañía Gaditana de Crédito", de "Conte y Cía, Sociedad en Comandita" y de la "Compañía Española de Navegación". Aparte del comercio y de las acciones en bancos y compañías de transporte, fue regidor del Ayuntamiento de Cádiz (1848, 49, 50 y 1854), Diputado Provincial, Jefe Superior honorario de la Administración Civil, vocal de la Junta Provincial de Instrucción Pública y Socio fundador del Casino Gaditano.

Se puede observar que salvo casos como los de Cristóbal Santos y otros de Medina Sidonia, la mayor parte de los protagonistas en la Desamortización en Medina, y que adquirieron las mayores extensiones de tierras, eran personas no residentes en esta ciudad. El caso de 1861 es realmente sintomático: ninguna de las $675 \mathrm{Ha}$. puestas en venta, en los casos estudiados, fue adquirida por un asidonense. Sin embargo, son personas dedicadas al comercio o propietarios que aprovechan la coyuntura para invertir y asegurar - mediante la pose- 
sión de tierras - una parte de su capital, en un proceso de ventas que facilitaba el proceso meramente capitalista de acumulación y especulación.

Concluimos. La Desamortización en Medina Sidonia sigue los rasgos generales de la española en general. De los objetivos propuestos al plantear el proceso, sólo algunos se lograron: se creó una clase de propietarios de bienes nacionales interesados en sostener - por puro egoísmo- el sistema liberal. Y se logró proporcionar al Estado de unos recursos económicos para aliviar la mala situación hacendística.

Pero otros muchos objetivos teóricos fracasaron:

No se mejoró la estructura de la propiedad, ni se creó la supuesta clase media agraria. Baste con recordar el proceso acumulativo de Cayetano Herrera para comprobarlo. Con ello se agudizaron los problemas del campo, al empeorar la situación de los antiguos arrendatarios, que en muchos casos pasan a ser jornaleros.

Observemos que en el caso de Medina Sidonia, ninguno de los colonos que conocemos logró alcanzar el rango de propietario de tierras desamortizadas, pese a que lo intentaron y pese a que en algunos casos tenían capital, como Francisco Pérez Noriega, que fue Diputado Provincial en 1863; sin embargo, las dos suertes que tenía arrendadas pasaron a manos de Cayetano Herrera.

Este puede ser el ejemplo final que resume todo el proceso: un adinerado arrendador asidonense, Francisco Pérez Noriega, vio cómo las tierras que disfrutaba pasaron a manos de Cayetano Herrera, un Magistrado de la Audiencia Territorial, absentista (residía en Sevilla) que posiblemente nunca llegó a cultivar, ni éstas, ni otras tierras que compró en la provincia. 